\title{
Assessment of radiographic morphology of mandibular condyles: a radiographic study
}

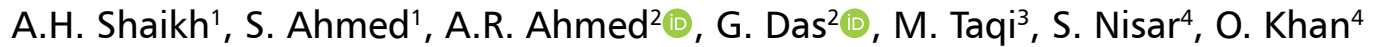 \\ ${ }^{1}$ Dow International Dental College, Dow University of Health Sciences, Karachi, Pakistan \\ ${ }^{2}$ College of Dentistry, King Khalid University, Abha, Saudi Arabia \\ ${ }^{3}$ Dow Dental College, Dow University of Health Sciences, Karachi, Pakistan \\ ${ }^{4}$ Drlshratulebad Khan Institute of Oral and Health Sciences, Dow University of Health Sciences, Karachi, Pakistan
}

[Received: 16 April 2021; Accepted: 4 May 2021; Early publication date: 17 May 2021]

\begin{abstract}
Background: Panoramic radiographs are the most common radiographic tool used by the dental clinicians to evaluate teeth, mandible and other related structures of the jaws. Mandibular condyle is an important anatomical landmark for facial growth, expressed in an upward and backward direction. The presentation of mandibular condyle differs widely among different group of ages and individuals. Materials and methods: The retrospective cross-sectional study was conducted from November 2018 to March 2019 at Dow International Dental College Karachi that includes radiographic evaluation of 500 mandibular condyles. All retrievable orthopantomograms were obtained and data were extracted regarding age, gender and condylar morphology.

Results: The morphological appearances of mandibular condyle have great variation among different age groups and subjects. Normally, we recognise five basic shapes i.e. oval, bird beak, crooked finger, diamond and mixed. Out of 250 pair of condylar heads that were evaluated, 50\% were oval, 40\% bird beak, $4.8 \%$ crooked finger and diamond $4.8 \%$.

Conclusions: All four morphological types of mandibular condyles were observed and the oval shape condyles were most prevalent among both genders and all age groups. In future studies, the inclusion of other parameters and large sample size may provide unique information. (Folia Morphol 2022; 81, 2: 481-486)
\end{abstract}

Key words: mandibular condyle, orthopantomogram, temporomandibular joint morphology

\section{INTRODUCTION}

Panoramic radiographs (orthopantomograms [OPG]) are the most routinely and widely used diagnostic tool used by the dental clinicians to get valuable information about teeth, mandible and other related structures of the jaw [13]. It gives us valuable knowledge about the anatomical variation of maxilla and mandible and also osseous changes or flattening happening with time [9]. Routine panoramic view has also been recommended by the American Academy of Oral and Maxillofacial Radiology for assessing the structural components of the temporomandibular joint (TMJ) because of the cost and risk of the relatively low radiation exposure associated with computed tomography [7].

Mandibular condyle is an important anatomical landmark for facial growth, expressed in an upward and backward direction [17]. The presentation of

Address for correspondence: Dr. G. Das, Assistant Professor Prosthodontics, College of Dentistry, King Khalid University, King Fahad Road, 61421 Abha, Saudi Arabia, e-mail: a_razzaq1@hotmail.com; drgotam2000@gmail.com

This article is available in open access under Creative Common Attribution-Non-Commercial-No Derivatives 4.0 International (CC BY-NC-ND 4.0) license, allowing to download articles and share them with others as long as they credit the authors and the publisher, but without permission to change them in any way or use them commercially. 
mandibular condyle differs widely among different age groups and individuals. Morphological variations depend upon developmental variation along with condylar remodelling to accommodate malocclusion, trauma and other pathological and developmental abnormalities [2]. Variability in the shapes and sizes of condyles helps to diagnose the TMJ disorders associated with malocclusions such as crossbite, deep bite, and open bite [3].

The mandibular condyle varies considerably both in size and shape. The typical condylar head has a convex arrangement throughout, and symmetry should exist between contralateral sides within the same individual $[12,17]$. Several studies have endeavoured to assess the morphology of human condyle. Past researchers evaluated a variety within the mandibular condyle shapes [12, 14]. Yale et al. [19] first classifies the shapes of the mandibular condyle as convex, flat and concave when having a superior view by examining the skulls of Terry collection. However, later Yale simplified classification into four categories flattened, convex, angled, rounded [19].

Upon surgical exposure, four different types of condyles shapes were noted, which include excavated form, oblique form, and the small round shape and flattened [11]. On the other hand, flat, convex, concave, round and angled types of condylar morphology were noted when computed tomography images were observed [8].

In Pakistan, limited data is available regarding the morphological appearance of the condyle. The thorough understanding of the morphological variations in the shape of the mandibular condyle is essential so that a standard variant can be distinguished from the abnormal condition. Therefore, this study aims to record different types of normal morphological variations of the condyle through an OPG. The objective of this study is to assess the frequency of different condylar morphological variations in both genders and age groups.

\section{MATERIALS AND METHODS}

\section{Study design and patients}

The retrospective cross-sectional study was conducted from November 2018 to March 2019 at Dow International Dental College Karachi; it included radiographic evaluation of 500 mandibular condyles. All retrievable OPGs were obtained, and necessary data was extracted regarding age, gender and condylar morphology. Ethical approval for this study was obtained from the Institutional Review Board, Dow University of Health Sciences.

Digital orthopantomograms (OPG) taken on Villa Rotograph EVO 3D, (exposure parameters being: $10 \mathrm{~mA}, 82 \mathrm{Kv}$ ) free of any projection errors, that showed a complete view of condyle on either side with optimum density and contrast were selected. The radiographs of the individuals with a history of TMJ dysfunction, occlusal discrepancy, pathological and developmental abnormalities were excluded.

Sum of 250 OPGs was visualized for a routine investigation. The OPGs were evaluated by two maxillofacial surgeons to determine the morphology of condyle. The statistical analysis was conducted using SPSS version 17. The participants were divided into three groups according to the age: (i) young adults (18-35 years), (ii) middle age (36-55 years), (iii) older adults ( 56 or above). Descriptive statistics were conducted to estimate the frequency of normal morphological variations of condyles. Chi-square test was conducted to assess the difference in frequency of normal condylar morphological variations about age and gender.

\section{Ethical approval}

All procedures performed in studies followed the ethical standards of the institutional research committee and the 1964 Helsinki declaration and its later amendments.

\section{RESULTS}

Total of 500 condyles from 250 OPGs was examined. Out of 250 radiographs, half of them belong to females, and half belong to males, as shown in Table 1 . In terms of age, the majority of radiographs were of participants belonging to middle age groups, as shown in Table 1.

The shapes of the condyles that have been identified in this study are: bird beak, oval, diamond, and crooked finger, as shown in Figures 1, 2, 3, and 4. The commonest form of condylar morphology was oval $(50 \%)$, followed by the bird beak (40\%), diamond $(4.8 \%)$ and crooked finger $(4.8 \%)$. The frequency of oval condylar morphology was $57.6 \%$ among males and $42.4 \%$ among female participant, as shown in Table 2 . In all age groups, the most dominant form of condylar morphology was oval, followed by the bird beak diamond and crooked finger. The frequency of oval condylar morphology was $36 \%$ in age group $1,44 \%$ in age group 2 and 20\% in age group 3, as shown in Table 2. 
Table 1. Demographic distribution of the participants according to gender and age

\begin{tabular}{lcccc}
\hline Gender & \multicolumn{4}{c}{ Age } \\
\cline { 2 - 5 } & Young adults (18-35 years) & Middle age (36-55 years) & Older adults (56 or above) & Total \\
\hline Male & $50(40 \%)$ & $54(43.2 \%)$ & $21(16.8 \%)$ & $125(100 \%)$ \\
Female & $38(30.4 \%)$ & $69(55.2 \%)$ & $18(14.4 \%)$ & $125(100 \%)$ \\
\hline
\end{tabular}

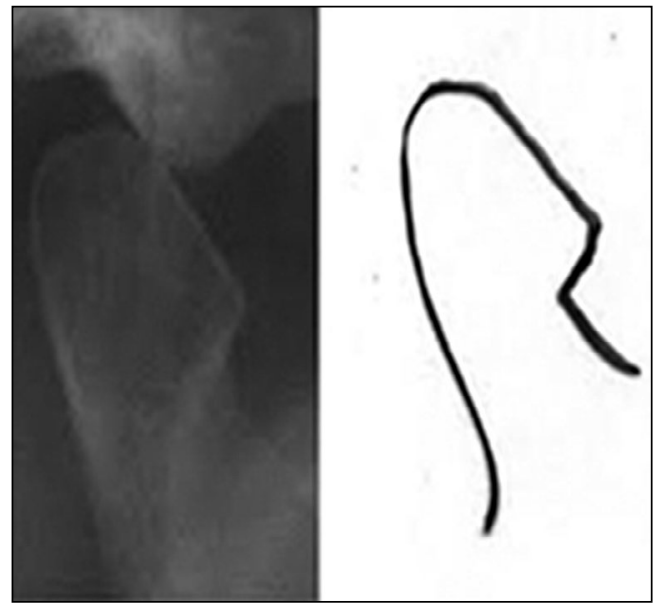

Figure 1. Type I - bird beak

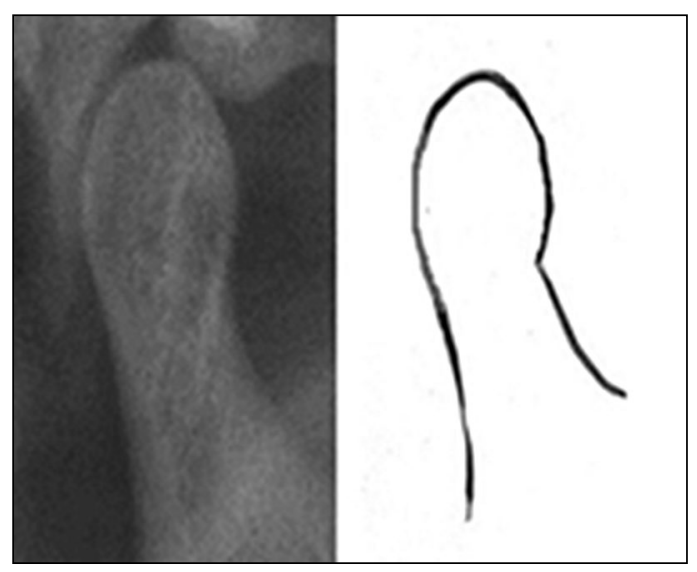

Figure 2. Type II - oval.

When the frequency of condylar morphological types was compared with the gender, it was observed that among male study participants, the oval condylar morphology was significantly higher $(p=0.016)$. On the other hand, among females study participants, the diamond condylar morphology was significantly higher $(p=0.018)$, as shown in Table 3 .

The frequency of condylar morphological types was compared with the age groups in Table 3. Among participants of age group 1, the frequen-

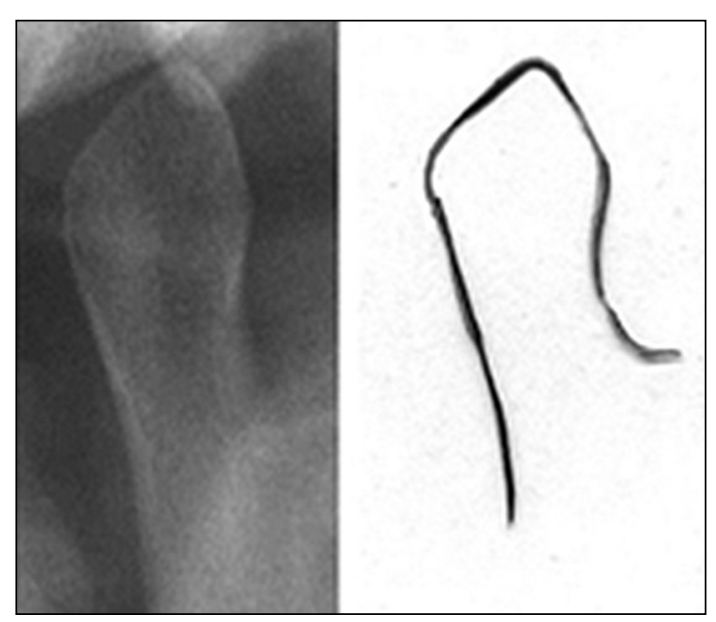

Figure 3. Type III — diamond.

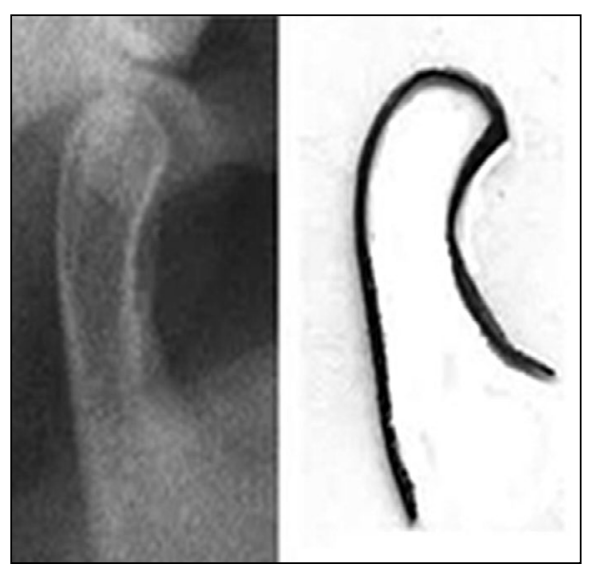

Figure 4. Type IV — crooked finger.

cy of diamond condyles was significantly lower as compared to other age groups. In the case of age group 2, the frequency of crooked finger condyles was significantly higher $(p=0.002)$ as compared to other age groups. Among participants of age group 3 the frequency of bird beak condyles were significantly lower $(p=0.001)$ as compared to other age groups and diamond condylar morphology was significantly higher $(p=0.0001)$ as compared to other age groups. 
Table 2. Distribution of the condylar morphology according to gender and age

\begin{tabular}{lcccc}
\hline & Bird beak & Diamond & Crooked finger & Oval \\
\hline Gender & & & & \\
Male & $48(47.5 \%)$ & $2(16.7 \%)$ & $3(25 \%)$ & $72(57.6 \%)$ \\
Female & $53(52.5 \%)$ & $10(83.3 \%)$ & $9(75 \%)$ & $53(42.4 \%)$ \\
Total & $101(100 \%)$ & $12(100 \%)$ & $12(100 \%)$ & $125(100 \%)$ \\
Age groups & & & & $45(36 \%)$ \\
Group 1 & $42(41.6 \%)$ & $0(0 \%)$ & $1(8.3 \%)$ & $55(44 \%)$ \\
Group 2 & $53(52.5 \%)$ & $4(33.3 \%)$ & $11(91.7 \%)$ & $25(20 \%)$ \\
Group 3 & $6(5.9 \%)$ & $8(66.7 \%)$ & $0(0 \%)$ & $125(100 \%)$ \\
Total & $101(100 \%)$ & $12(100 \%)$ & $12(100 \%)$ & \\
\hline
\end{tabular}

Group 1: 18-35 years old, Group 2: 36-55 years old, Group 3: 56 or above

Table 3. Comparing the frequency of condylar morphology between both genders

\begin{tabular}{|c|c|c|c|c|c|c|c|c|c|c|c|c|}
\hline \multirow[t]{2}{*}{ Gender } & \multicolumn{3}{|c|}{ Bird beak } & \multicolumn{3}{|c|}{ Diamond } & \multicolumn{3}{|c|}{ Crooked finger } & \multicolumn{3}{|c|}{ Oval } \\
\hline & Yes & No & $\mathbf{P}$ & Yes & No & $\mathbf{P}$ & Yes & No & $\mathbf{P}$ & Yes & No & $\mathbf{P}$ \\
\hline Male & $48(38.4 \%)$ & 77 (61.6\%) & 0.51 & $2(1.6 \%)$ & $123(98.4 \%)$ & 0.018 & $3(2.4 \%)$ & $122(97.6 \%)$ & 0.076 & $72(57.6 \%)$ & $53(42.4 \%)$ & 0.016 \\
\hline Female & $53(57.6 \%)$ & $72(42.4 \%)$ & & $10(8 \%)$ & $115(92 \%)$ & & $9(7.2 \%)$ & $116(92.8 \%)$ & & $53(42.4 \%)$ & 72 (57.6\%) & \\
\hline
\end{tabular}

Chi-square test

\section{DISCUSSION}

The morphological appearances of mandibular condyle have great variation among different age groups and subjects [15, 18]. Normally, we recognize five basic shapes, i.e. oval, bird beak, crooked finger, diamond and mixed. In Pakistan, limited data is available regarding the morphological appearance of the condyle. Therefore the present study highlights the prevalent radiographic shapes of the condylar head-on OPG. Out of 250 pair of condylar heads that were evaluated, $50 \%$ were oval, $40 \%$ bird beak, $4.8 \%$ crooked finger and diamond $4.8 \%$. In our study, the oval condylar morphology was most common and significantly higher among male individuals (Table 3). The studies reported by Choudhary et al. [6] and Ribeiro et al. [14] pertaining to the Brazilian and East Indian population respectively showed round/ /oval shape to be common in both sexes which goes in accordance with our study.

The morphological knowledge of the TMJ is an important tool for evaluation of normal growth and development. This may also be helpful in the near future for the development of forensic odontology $[6,8,17]$. The growth of mandibular condyle is indicated in an upward and backward direction. It is considered as major areas of facial growth. The appearance and the shape of mandibular condyle vary enormously among individuals and different age groups, which is in accordance with the present study [11-13].

The present study on the radiological examination using OPG revealed flat, pointed, angled and round condylar morphology. Similarly, several other studies also showed the bird beak, oval, diamond, and crooked finger type condylar morphology [1, 10, 18]. In our study the second most common condylar morphology observed was bird beak. The frequency of bird beak condylar morphology was higher among females as compared to males. However, no statistically significant difference was observed when both genders were compared (Table 3). Similarly, Sonal et al. (2016) [16] also reported the bird beak as a second most common condylar morphology among females. On the other hand, the diamond and crooked finger morphology were a rarity $[4,18]$.

We compared the participant age with the condylar morphology. However, to our knowledge, no such data is reported in previous studies; thus, a comparison is not possible. The diamond shape condyles were significantly higher among participants of age group 3 as compared to other age groups (Table 4). The frequency of crooked finger condyles was significantly 
Table 4. Comparing the frequency of condylar morphology between age groups

\begin{tabular}{|c|c|c|c|c|c|c|c|c|c|c|c|c|}
\hline \multirow[t]{2}{*}{ Age group } & \multicolumn{3}{|c|}{ Bird beak } & \multicolumn{3}{|c|}{ Diamond } & \multicolumn{3}{|c|}{ Crooked finger } & \multicolumn{3}{|c|}{ Oval } \\
\hline & Yes & No & $\mathbf{P}$ & Yes & No & $\mathbf{P}$ & Yes & No & $\mathbf{P}$ & Yes & No & $\mathbf{P}$ \\
\hline Group 1 & $42(47.7 \%)$ & 46 (52.3\%) & 0.105 & $0(0 \%)$ & 88 (100\%) & 0.010 & $1(1.1 \%)$ & 87 (98.9\%) & 0.061 & $45(51.1 \%)$ & 43 (48.9\%) & 0.895 \\
\hline Groups 2, 3 & $59(36.4 \%)$ & $103(63.6 \%)$ & & $12(7.4 \%)$ & $150(92.6 \%)$ & & $11(6.8 \%)$ & $151(93.2 \%)$ & & $80(49.4 \%)$ & $82(50.6 \%)$ & \\
\hline Group 2 & $53(43.1 \%)$ & 70 (56.9\%) & 0.440 & $4(3.3 \%)$ & $119(96.7 \%)$ & 0.377 & $11(8.9 \%)$ & $112(91.1 \%)$ & 0.002 & $55(44.7 \%)$ & 68 (55.3\%) & 0.129 \\
\hline Groups 1, 3 & $48(37.8 \%)$ & $79(62.2 \%)$ & & $8(6.3 \%)$ & $119(93.7 \%)$ & & $1(0.8 \%)$ & $126(99.2 \%)$ & & 70 (55.1\%) & 57 (44.9\%) & \\
\hline Group 3 & $6(15.4 \%)$ & $33(84.6 \%)$ & 0.001 & $8(20.5 \%)$ & 31 (79.5\%) & 0.001 & $0(0 \%)$ & $39(100 \%)$ & 0.223 & $25(64.1 \%)$ & $14(35.9 \%)$ & 0.080 \\
\hline Groups 1, 2 & $95(45 \%)$ & $116(55 \%)$ & & $4(1.9 \%)$ & $207(98.1 \%)$ & & $12(5.7 \%)$ & $199(94.3 \%)$ & & $100(47.4 \%)$ & $111(52.6 \%)$ & \\
\hline
\end{tabular}

Group 1: 18-35 years old, Group 2: 36-55 years old, Group 3: 56 or above; Chi-square test

higher among participants of age group 2 (Table 4). The frequency of bird beak condyles was significantly higher among group 1 and 2 as compared to group 3 (Table 4).

In comparison of our results, several other studies investigated that it is very important to evaluate condyle morphology with changes in condyle surface shapes, radiological dimensional measurements with malocclusion. A study reported that there was a significant relation between open bite and erosion of the head of the condyle. Ari-Demirkaya et al. [5] found that there was no difference between open, deep or normal bite groups in subjects with different condylar morphology.

Currently, various advanced radiographic modalities are available, such as computed tomography scan, cone beam volumetric imaging, which can give detailed information of the condyle. However, oral health practitioners usually prefer OPG to screen TMJ. The possible explanation due to which oral health practitioners still prefers OPG include favourable cost-benefit relationship, low doses of radiation exposure, ease of prescription and lack of image superimposition $[4,14,15]$. The use of OPG has its limitations such as a two-dimensional view. In addition to that, the limitations of this study include small sample size and lack of examiner reliability.

\section{CONCLUSIONS}

In conclusion, all four morphological types of mandibular condyles were observed and the oval shape condyles were most prevalent among both genders and all age groups. In future studies, the inclusion of other parameters and large sample size may provide unique information.

\section{Acknowledgements and funding}

The authors extend their appreciation to the Deanship of Scientific Research at King Khalid University, KSA for funding this work through research groups programme under Grant No. RGP.1/343/42.

Conflict of interest: None declared

\section{REFERENCES}

1. Ahmed MA, Subramaniam N. Prevalence of morphological variation of condyle in patients undergoing routine dental treatment-A retrospective orthopantomographic study. Drug Invention Today. 2019; 12(9).

2. Ahn SJ, Kim TW, Lee DY, et al. Evaluation of internal derangement of the temporomandibular joint by panoramic radiographs compared with magnetic resonance imaging. Am J Orthod Dentofacial Orthop. 2006; 129(4): 479-485, doi: 10.1016/j.ajodo.2005.12.009, indexed in Pubmed: 16627173.

3. Al-Saedi Al, Riad AT, AL-Jasim N, et al. A panoramic study of the morphology of mandibular condyle in a sample of population from basrah city. Int J Morphol. 2020; 38(6): 1707-1712, doi: 10.4067/s0717-95022020000601707.

4. Anisuzzaman MM, Khan S, Khan M, et al. Evaluation of mandibular condylar morphology by orthopantomogram in bangladeshi population. Update Dental Coll J. 2019; 9(1): 29-31, doi: 10.3329/updcj.v9i1.41203.

5. Ari-Demirkaya A, Biren S, Ozkan H, et al. Comparison of deep bite and open bite cases: normative data for condylar positions, paths and radiographic appearances. J Oral Rehabil. 2004; 31 (3): 213-224, doi: 10.1046/j.0305182X.2003.01236.x, indexed in Pubmed: 15025653.

6. Choudhary A, Ahuja US, Rathore A, et al. Association of temporomandibular joint morphology in patients with and without temporomandibular joint dysfunction: A cone-beam computed tomography based study. Dent Res J (Isfahan). 2020; 17(5): 338-346, indexed in Pubmed: 33343841.

7. Epstein JB, Caldwell J, Black G. The utility of panoramic imaging of the temporomandibular joint in patients with temporomandibular disorders. Oral Surg Oral Med Oral Pathol Oral Radiol Endod. 2001; 92(2): 236-239, 
doi: 10.1067/moe.2001.114158, indexed in Pubmed: 11505273.

8. Hegde S, Praveen BN, Shetty SR. Morphological and radiological variations of mandibular condyles in health and diseases: a systematic review. Dentistry. 2013; 03(01), doi: 10.4172/2161-1122.1000154.

9. Honda E, Yoshino N, Sasaki T. Condylar appearance in panoramic radiograms of asymptomatic subjects and patients with temporomandibular disorders. Oral Radiol. 1994; 10(2): 43-53, doi: 10.1007/bf02390715.

10. Jawahar A, Maragathavalli G. Analysis of condylar morphological variations using digital panoramic radiographs-a retrospective study. Indian J Public Health Res Develop. 2019; 10(11): 3450, doi: 10.5958/09765506.2019.04116.0.

11. Juniper RP. The shape of the condyle and position of the meniscus in temporomandibular joint dysfunction. $\mathrm{Br} J$ Oral Maxillofac Surg. 1994; 32(2): 71-76, doi: 10.1016/0266-4356(94)90130-9, indexed in Pubmed: 8199150.

12. Katsavrias EG, Halazonetis DJ. Condyle and fossa shape in Class II and Class III skeletal patterns: a morphometric tomographic study. Am J Orthod Dentofacial Orthop. 2005; 128(3): 337-346, doi: 10.1016/j.ajodo.2004.05.024, indexed in Pubmed: 16168330.

13. Momjian A, Courvoisier D, Kiliaridis S, et al. Reliability of computational measurement of the condyles on digital panoramic radiographs. Dentomaxillofac Radiol. 2011; 40(7): 444-450, doi: 10.1259/dmfr/83507370, indexed in Pubmed: 21960403.

14. Ribeiro E, Sanches M, Alonso L, et al. Shape and symmetry of human condyle and mandibular fossa. Int J Odontostomatol. 2015; 9(1): 65-72, doi: 10.4067/s0718$381 \times 2015000100010$.

15. Singh B, Kumar NR, Balan A, et al. Evaluation of normal morphology of mandibular condyle: a radiographic survey. J Clin Imaging Sci. 2020; 10: 51, doi: 10.25259/ JCIS_84_2020, indexed in Pubmed: 32874756.

16. Sonal V, Sandeep P, Kapil G, et al. Evaluation of condylar morphology using panoramic radiography. J Adv Clin Res Ins. 2016; 3: 5-8, doi: 10.15713/ins.jcri.94.

17. Valladares Neto J, Estrela C, Bueno MR, et al. Mandibular condyle dimensional changes in subjects from 3 to 20 years of age using cone-beam computed tomography: a preliminary study. Dental Press J Orthodontics. 2010; 15(5): 172-81.

18. Yalcin ED, Ararat E. Cone-Beam computed tomography study of mandibular condylar morphology. J Craniofac Surg. 2019; 30(8): 2621-2624, doi: 10.1097/ SCS.0000000000005699, indexed in Pubmed: 31261335.

19. Yale SH, Allison BD, Hauptfuehrer JD. An epidemiological assessment of mandibular condyle morphology. Oral Surg Oral Med Oral Pathol. 1966; 21(2): 169-177, doi: 10.1016/00304220(66)90238-6, indexed in Pubmed: 5215976. 